\title{
anthocyanosides in a
} multiple oral dose on night vision

\begin{abstract}
Purpose In view of research demonstrating the ability of anthocyanosides in a multiple oral dose to improve night vision in normal individuals, we assessed their effect on three night vision tests: full-field absolute scotopic retinal threshold (SRT), dark adaptation rate (DAR) and mesopic contrast sensitivity (MCS). Methods In a double-masked, placebocontrolled, cross-over study, 18 young normal volunteers were randomly assigned to one of three different regimens of multiple oral administrations of 12 and $24 \mathrm{mg}$ anthocyanosides, and a placebo, given twice daily for 4 days. A 2 week washout period was allowed between each 4 day treatment period. SRT, DAR and MCS was tested 1 day before and at days 1, 2, 3 and 4 during the treatment period.

Results No significant effect was found on any of the three above-mentioned night vision tests. The study had a power of 0.95 to detect a $0.1 \mathrm{log}$ unit improvement in SRT and $0.5 \mathrm{log}$ unit improvement in MCS.

Conclusions Multiple oral administrations of 12 and $24 \mathrm{mg}$ anthocyanosides twice a day appear to lack significant effect on night vision tests.
\end{abstract}

Key words Anthocyanosides, Blueberry, Night vision

Anthocyanosides are water-soluble pigments that appear in nature predominantly as glycosides. The richest source is the blueberry plant (Vaccinium myrtillus). Compounds extracted from blueberries containing predominantly anthocyanosides were reported to improve night vision functions in human subjects after a multiple oral administration. ${ }^{1-3}$ The exact biochemical influence of anthocyanosides on the neurosensory retina is not known. ${ }^{4-8}$ It has been speculated that anthocyanosides accelerate the resynthesis of rhodopsin ${ }^{4}$ and modulate retinal enzymatic activity. ${ }^{5}$ In a previous study we were unable to detect a significant effect of anthocyanosides in a single oral dose on night vision of normal individuals. ${ }^{9}$

In the current study we assessed the effect of multiple doses of oral anthocyanosides on fullfield absolute scotopic retinal threshold (SRT), full-field dark adaptation rate (DAR) and mesopic contrast sensitivity (MCS) in human subjects. SRT, DAR and MCS were chosen for a number of reasons described in detail in our previous report, the most important one being our recent finding that SRT, DAR and MCS are directly related to the ability to identify field targets at night. ${ }^{10}$ To the best of our knowledge, there is no published double-masked, placebocontrolled, cross-over study on the effects of multiple oral administrations of different doses of anthocyanosides on night vision tests.

\section{Subjects and methods}

Subjects were 18 healthy male volunteers, 21-30 years of age (mean $26 \pm 2.1$ years), who had a best corrected mesopic ( 1 foot-lambert) visual acuity of $20 / 25$ or better (mean 20/22.5 \pm 2.0 ). Twelve subjects were emmetropic, and 6 had myopia from $-5.00 \mathrm{D}$ to $-1.00 \mathrm{D}$, the greatest cylinder being $1.25 \mathrm{D}$ in one case.

After obtaining their informed consent (approved by the Tel Aviv University Helsinki Committee), subjects were randomly assigned to one of three groups. Each group was given a different regimen of multiple oral administrations of 12 and $24 \mathrm{mg}$ of anthocyanosides and a placebo, given twice daily for 4 days, as detailed in Table 1. A 2 week washout period intervened between each 4 day treatment period.

The double-masked, placebo-controlled, cross-over study was carried out in the winter (January-February 1996). MCS, DAR and SRT were tested in that order, 1 day before and daily during the 4 day treatment period (3-5 h following the morning drug application). Tablets of Strix (Halsoprodukter, Forserum, Sweden) containing $12 \mathrm{mg}$ anthocyanosides (blueberry extract) and $2 \mathrm{mg}$ beta-carotene, and placebo tablets (CTS, Israel), were used. 
Table 1. Treatment regimens of anthocyanosides given twice daily for 4 days

\begin{tabular}{cccc}
\hline Group & Week 1 & Week 4 & Week 7 \\
\hline $1(n=6)$ & $12 \mathrm{mg}$ & $24 \mathrm{mg}$ & Placebo \\
$2(n=6)$ & $24 \mathrm{mg}$ & Placebo & $12 \mathrm{mg}$ \\
$3(n=6)$ & Placebo & $12 \mathrm{mg}$ & $24 \mathrm{mg}$ \\
\hline
\end{tabular}

MCS was measured with the MCT 8000 (Vistech Consultants, Dayton $\mathrm{OH}$ ), consisting of circular patches of sine-wave gratings varying in spatial frequency, contrast and orientation. Each target has seven circular discs, each one with a sine-wave grating of a fixed spatial frequency. The gratings are vertical or tilted $15^{\circ}$ to the right or left, and the contrast of the gratings progressively decreases from disc 1 to 7 . The contrast sensitivity score is the last consecutive disc whose orientation is correctly identified (using the spatial three-alternative forced-choice method). ${ }^{11}$ The spatial frequencies displayed are 1.5, 3, 6, 12 and 18 cycles/degree (cpd). MCS was measured in the right eye of each subject using a mesopic background luminance of 1 foot-lambert with corrections for distance worn as needed.

SRT and DAR were measured binocularly following bleaching for $5 \mathrm{~min}$ (3000 asb). A Goldmann-Weekers dark adaptometer (Haag-Streit, Bern, Switzerland) was employed, which presents flickering $(0.5 \mathrm{~Hz})$, diffuse, white-light ganzfeld stimuli. ${ }^{12}$ The instrument was calibrated for stimulus illuminance and bleaching luminance before each session. No fixation light was used for retinal sensitivity measurements; the subject was instructed to look straight ahead into the centre of the bowl as the luminance of the whole-field flickering stimulus was increased progressively at a fixed rate until detected. Following a response, the luminance was reduced to its lowest level and retinal sensitivity determined two more times. The DAR score was the average of three consecutive measurements of retinal threshold at $10 \mathrm{~min}$ after dark adaptation, which is the early phase of the dark adaptation of the rods (perhaps $3 \mathrm{~min}$ past the rod-cone break). SRT was determined in the same way, after 30 min of dark adaptation.

Data were stored and processed by the SAS Statistical Package for Personal Computers. ${ }^{13}$ The general linear model procedure (within-subject repeated measures analysis of variance, ANOVA) was used to compare the effect of various doses of anthocyanosides. Results from all tests were considered statistically significant at $p<0.05$.

Table 2. Mean full-field scotopic retinal threshold (SRT) values (log units $\pm S D)$ after 30 min of dark adaption $(n=18)$

\begin{tabular}{cccc}
\hline & \multicolumn{3}{c}{ Anthocyanosides } \\
\cline { 2 - 3 } Time (days) & $12 \mathrm{mg}$ b.i.d. & $24 \mathrm{mg}$ b.i.d. & Placebo \\
\hline 0 & $2.16 \pm 0.14$ & $2.09 \pm 0.17$ & $2.06 \pm 0.16$ \\
1 & $2.07 \pm 0.22$ & $2.09 \pm 0.11$ & $2.08 \pm 0.20$ \\
2 & $2.16 \pm 0.19$ & $2.03 \pm 0.20$ & $2.08 \pm 0.15$ \\
3 & $2.08 \pm 0.14$ & $2.05 \pm 0.18$ & $2.02 \pm 0.18$ \\
4 & $2.08 \pm 0.17$ & $2.01 \pm 0.16$ & $2.11 \pm 0.21$ \\
\hline
\end{tabular}

Table 3. Mean dark adaptation rate (DAR) values (log units $\pm S D)$ after 10 min of dark adaptation $(n=18)$

\begin{tabular}{cccc}
\hline & \multicolumn{3}{c}{ Anthocyanosides } \\
\cline { 2 - 3 } Time (days) & $12 \mathrm{mg}$ b.i.d. & $24 \mathrm{mg}$ b.i.d. & Placebo \\
\hline 0 & $3.15 \pm 0.21$ & $3.15 \pm 0.11$ & $3.14 \pm 0.11$ \\
1 & $3.14 \pm 0.32$ & $3.15 \pm 0.11$ & $3.14 \pm 0.08$ \\
2 & $3.14 \pm 0.12$ & $3.10 \pm 0.16$ & $3.15 \pm 0.26$ \\
3 & $3.12 \pm 0.15$ & $3.12 \pm 0.10$ & $3.10 \pm 0.11$ \\
4 & $3.10 \pm 0.12$ & $3.09 \pm 0.10$ & $3.10 \pm 0.09$ \\
\hline
\end{tabular}

\section{Results}

There were no significant differences in the mean SRT $(p=0.12$, Table 2$)$ or DAR $(p=0.86$, Table 3$)$ values between the anthocyanoside-treated groups and the control group during the 4 day drug administration period (within-subject repeated measures ANOVA). Nor were there significant differences in the mean values of MCS (average of 1.5, 3, 6, and $12 \mathrm{cpd}$ ) ( $p=0.73$, Table 4 ) between the anthocyanoside-treated groups and the control group during the 4 day drug administration (within-subject repeated measures ANOVA). Similar results (data not shown) were obtained for each of the $4 \mathrm{cpd}$ rates of MCS: 1.5, 3, 6 and $12 \mathrm{cpd}$.

The study had a power of 0.95 to detect a $0.1 \mathrm{log}$ unit improvement in SRT and 0.5 log unit improvement in MCS. ${ }^{14}$

\section{Discussion}

Several scientific publications in the 1960s and early 1970s reported improvement of night vision functions in normal individuals after a multiple oral administration of anthocyanosides. ${ }^{1,15,16}$ Indeed, the authors of this paper found over 50 sites on the Internet which claim improvement of night vision following oral consumption of blueberries or blueberry-extract.

The ability to improve night vision functions of normal persons with anthocyanosides is attractive in view of the many complaints of difficulty driving or walking at night in subjects with no ocular disease. In the present study we found no effect of multiple-dose anthocyanosides on any of the three night vision tests previously found by us to be good predictors of actual night performance. ${ }^{10}$

Our findings contrast with those of studies carried out 20-30 years ago, ${ }^{1,15,16}$ probably because of differences in study design and populations. Our double-masked, placebo-controlled, cross-over study enabled more

Table 4. Mean values ( $\log$ units $\pm S D$ ) of mesopic contrast sensitivity (MCS): average of 1.5, 3, 6 and $12 \mathrm{cpd}(n=18)$

\begin{tabular}{cccc}
\hline & \multicolumn{3}{c}{ Anthocyanosides } \\
\cline { 2 - 3 } Time (days) & $12 \mathrm{mg}$ b.i.d. & $24 \mathrm{mg} \mathrm{b.i.d.}$ & Placebo \\
\hline 0 & $5.11 \pm 0.65$ & $5.12 \pm 0.70$ & $5.04 \pm 0.74$ \\
1 & $5.08 \pm 0.58$ & $5.15 \pm 0.79$ & $5.07 \pm 0.77$ \\
2 & $5.33 \pm 0.60$ & $5.22 \pm 0.77$ & $5.27 \pm 0.66$ \\
3 & $5.32 \pm 0.79$ & $5.19 \pm 0.74$ & $5.21 \pm 0.88$ \\
4 & $5.27 \pm 0.73$ & $5.33 \pm 0.71$ & $5.32 \pm 0.69$ \\
\hline
\end{tabular}


accurate evaluation of the parameters being tested. Moreover, anthocyanosides might have had no effect on the young subjects in our study who had excellent night vision, while they may improve the scores in individuals with low or moderate night vision ability.

The discrepancy in results could also be due to differences in extracts of blueberries from different parts of the world, which might contain unequal amounts of active ingredients other than anthocyanosides.

Nevertheless, our inability to demonstrate a beneficial effect of anthocyanosides on night vision even with a multiple dose suggest that such claims as 'blueberry extracts improve your night vision' should be viewed with caution. However, our study measured the effect of 4 days of treatment, and perhaps a longer duration ( 2 weeks) of anthocyanoside treatment should be checked.

\section{References}

1. Jayle GE, Aubert L. Action des glucosides d'anthocyanes sur la vision scotopique et mesopique du sujet normal. Therapie 1964;19:171-85.

2. Belleoud L, Leluan D, Boyer Y. Etude des effets des glucosides d'Anthocyan sur la vision nocturne des controleurs d'Aerodrome. Rev Med Aeronautique Spatiale 1966;18:3-7.

3. Gloria E, Perla A. Effeto degli antocianosidi sulla soglia visiva assoluta. Ann Ottalmol 1966;92:595-607.

4. Alfieri R, Sole P. Influence des anthocyanosides administrés par voie oro-perlinguale sur l'adapto-electroretinogramme (AERG) en lumière rouge chez l'homme. Soc Biol ClermontFerrand 1966;160:1590-3.
5. Cluzel C, Bastide P, Wegman R, Tronche P. Activités enzymatiques de la retine et anthocyanosides extraits de Vaccinium myrtillus. Biochem Pharmacol 1970;19:2295-302.

6. Magnasco A, Zingirian M. Influence of anthocyanosides on the mesopic differential threshold of the retina. Ann Ottalmol Clin Ocul 1966;92:188-93.

7. Bastide P, Rouher F, Tronche P. Rhodopsin and anthocyanosides: apropos of various experimental facts. Bull Soc Ophtalmol Fr 1968;68:801-7.

8. Bronner MA, Hissler R, Franck H. Action of anthocyanosides and vitamin $A$ on the electro-oculogram of normal subjects. Bull Soc Ophtalmol Fr 1976;76:157-61.

9. Levy Y, Glovinsky Y. The effect of anthocyanosides on night vision. Eye 1998;12:967-9.

10. Glovinsky Y, Belkin M, Hammer A. Night vision in young individuals: correlation between laboratory findings and performance in the field. Invest Ophthalmol Vis Sci 1992;33/4(Suppl):3621.

11. Miller D. Glare and contrast sensitivity testing. In: Tasman W, Jaeger EA, editors. Duane's clinical ophthalmology. vol 1. Hagerstown: Lippincott-Raven, 1996:1-19.

12. Goldmann-Weekers dark adaptometer manual. Bern, Switzerland: Haag-Streit, pp 1-16.

13. SAS Institute. SAS/STATTM guide for personal computers, version 6. Cary, NC: SAS Institute, 1987.

14. Campbell MJ, Machin D. Sample size calculations. In: Medical statistics: a commonsense approach, 2 nd ed. Chichester: Wiley, 1993:156-7.

15. Rouher F, Sole P, Offret G, Bernard JA. Mise en evidence adaptoelectroretinographique de l'action d'une cyanidine sur la vision nocturne. Arch Ophtalmol 1972;32:531-40.

16. Sole P, Rigal D, Peyresblanques J. Effets du chlorure de cyaninosides et de Heleniene sur la vision mesopique et scotopique dans la myopie et ihemeralopie. J Fr Ophtalmol 1984;7:35-9. 